\title{
EXPERIMENTAL STUDY OF FAILURE MECHANISMS IN BRITTLE CONSTRUCTION MATERIALS BY MEANS OF X-RAY MICROFOCUS COMPUTED TOMOGRAPHY
}

\author{
E. VERSTRYNGE ${ }^{*}{ }^{\dagger}$, C. VAN STEEN ${ }^{\dagger}$, J. ANDRIES $^{\dagger}$, K. VAN BALEN $^{\dagger}$, L. $^{+}$ \\ VANDEWALLE ${ }^{\dagger}$ AND M. WEVERS ${ }^{\dagger}$ \\ ${ }^{\dagger}$ KU Leuven, Civil Engineering Department \\ Leuven, Belgium \\ e-mail: els.verstrynge@kuleuven.be; charlotte.vansteen@kuleuven.be; joren.andries@kuleuven.be; \\ koenraad.vanbalen@kuleuven.be; lucie.vandewalle@kuleuven.be \\ ${ }^{\dagger}$ KU Leuven, Department of Metallurgy and Materials Engineering \\ Leuven, Belgium \\ e-mail: martine.wevers@,kuleuven.be
}

Key words: Microfocus X-ray computed tomography, masonry, sandstone, fibre reinforced concrete, micro fracture, 3D visualization.

\begin{abstract}
X-ray microfocus computed tomography (CT) is a powerful tool in the $3 \mathrm{D}$ visualization of fracture initiation and propagation in brittle materials, based on the attenuation of X-rays. Aim of this paper is to present the experience obtained at the Building Materials and Building Technology research group in using CT for the experimental study of failure mechanisms in brittle construction materials during three test programs, focusing on following issues: (i) triaxial behaviour of mortar joints, (ii) effect of pore saturation on micro fracture in sandstone and (iii) influence of flow distance on fibre distribution and orientation in fibre reinforced concrete. The resolution limit of the applied system is in the order of micro meters (microCT). Common goal of the presented experimental programs was to analyse the material's inner structure and fracture propagation at microscale, in support of studying local failure mechanisms and developing numerical models. For each test program, setup optimization and resulting failure modes will be discussed. Several types of in-house-made loading stages were applied for observation of step-wise induced failure mechanisms. As a general conclusion, most test results supported the theoretical framework relevant to the effects of varying conditions (relative stiffness, pore saturation, viscosity) on the observed failure modes. However, sample size / image resolution balance remains an important focus point. Additionally, future research is briefly discussed, in relation to the experience gained in the described test programs.
\end{abstract}

\section{INTRODUCTION}

X-ray Computed Tomography (CT) is a non-destructive observation technique that was initially implemented in the medical field but has found its way into materials research [1]. The technique allows to visualize the inner structure of a non-transparent specimen, based on the attenuation of X-rays [2]. It can be used to study the internal structure of porous building materials such as mortar, bricks, concrete paste and natural stone [3-6]. In medical applications, a scanner-detector system rotates around an object while in applications of microfocus CT or microCT, the object rotates and the scanner-detector system remains immobile. 
A radioactive source is placed on one side of the sample and a detector is placed on the opposite side [7] (fig.1). A polychromatic beam of X-ray photons (i.e., photons with varying energy levels) with an incident intensity, $\mathrm{I}_{0}$, is produced by the X-ray source. While X-ray photons pass through the object, with thickness $t$, a portion of the incident intensity is absorbed and scattered (i.e., attenuated). The transmitted intensity $\mathrm{I}$ is then recorded by the detector. For monochromatic X-rays (i.e., photons with a single energy level), the Beer-Lambert law (1) describes the relation between the incident intensity $\mathrm{I}_{0}$ and the transmitted intensity I [8]:

$$
I=I_{0} \cdot \exp (-\mu \cdot t)
$$

where, $\mu$ is the linear attenuation coefficient $\left(\mathrm{cm}^{-1}\right)$. The density of the material determines the rate of attenuation. As mentioned, polychromatic X-rays photons instead of monochromatic X-ray photons are used while scanning. Photons with lower energy will be absorbed faster and more easily, causing the average energy to increase. This phenomenon is called beam hardening [9]. To account for this discrepancy, the linear attenuation coefficient, $\mu$ in Eq. (1) must be replaced by the effective attenuation coefficient $\mu_{\mathrm{ef}}[6]$.

The attenuated beam of X-ray photons is recorded by the detector and converted into a matrix of incident intensities. The intensities are coupled to a gray scale resulting in a $2 \mathrm{D}$ projection image. The object then rotates over a small angle and a new image is taken. This procedure is repeated till the object has been rotated for $180^{\circ}$ or $360^{\circ}$. These images are used as input for reconstruction software, which composes a 3D array of density values (fig. 1). The result can be used to produce horizontal or vertical sections and to analyse $2 \mathrm{D}$ and $3 \mathrm{D}$ morphological parameters. The limit of resolution of the system is in order of micrometers (microCT). For advanced and expensive systems, a performance down to nanometers (nanoCT) is possible.

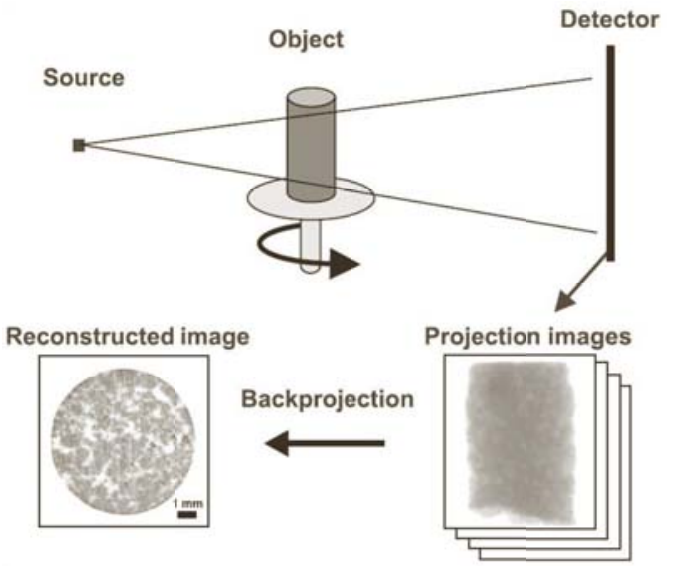

Figure 1: Principle of reconstruction of sections from radiography images in microCT [10]

This paper discusses the experience obtained at the Building Materials and Building Technology research group in using microCT for the experimental study of failure mechanisms in brittle construction materials during three test programs.

Common goal of the presented experimental programs was to analyse the material's inner structure and fracture propagation at microscale, in support of studying local failure mechanisms and developing numerical models. The presented test programs concern:

- The triaxial behaviour of mortar joints with different mortar composition (lime, cement, hybrid binders), and thus varying mortar-brick stiffness ratio.

- Fracture growth in three types of ferruginous sandstone samples (low to moderate cementation), which were subjected to stepwise compressive loading in dry and water-saturated conditions.

- Influence of flow distance on fibre distribution and orientation in two types of steel fibre reinforced self-compacting concrete (with medium and high viscosity, but similar slump-flow value).

For each test program, setup optimization and resulting failure modes will be presented (Section 2-4). In Section 5, an overall discussion of the results and experiences, gained from the test programs is presented, and future research is highlighted. 


\section{THE FAILURE MECHANISM OF BRICK MASONRY COUPLETS}

\subsection{Problem statement}

The nature of the failure mechanism of masonry under compression depends on the relative properties of the brick and mortar [11]. To study this effect, the failure mechanism of brick masonry couplets with cement and lime mortars was investigated under compressive loading using microCT combined with an insitu mechanical press [10]. It is well-known that the ratio of stiffness of both materials has an important effect. As the interface between brick and mortar is the weakest part in masonry, an unequal stiffness (Young's modulus E, shear modulus G, Poisson's ratio v) may induce tensile stress or shear stress near the interface. The generally hypothesis is that [12] (Fig. 2):

- if the brick's stiffness is higher than the mortar's stiffness, the mortar will tend to expand more laterally, which causes tensile stress in the brick;

- if the mortar's stiffness is higher than the brick's stiffness, the brick will tend to expand more laterally, which causes tensile stress in the mortar;

- if stiffness is comparable, a homogeneous behaviour is expected, with typically the formation of conical shear planes.
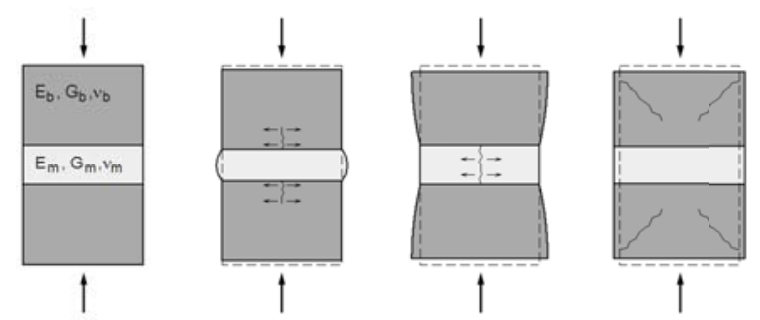

Figure 2: Hypothesis for deformation and crack initiation for three different cases of stiffness ratio between mortar and brick [10]

\subsection{Test setup}

For the test program, a moulded clay brick, type "Spanish Red" by Wienerberger, was used [10]. The mechanical characteristics are comparable to historical masonry. Four types of mortar were selected, and one of them had two different curing procedures [13], which brings the total to five (cement mortar, hydraulic lime mortar, hybrid lime-cement mortar, partially and fully carbonated airhardening lime mortar). The aim was to have a wide spectrum of strength in order to compare different failure modes. The sand is a fine siliceous quarry sand. Detailed properties of the mortars can be found in [10].

For the cylindrical specimens, a diameter of $29 \mathrm{~mm}$ and a joint thickness of $12 \mathrm{~mm}$ was chosen. The height of the upper and lower brick cylinder was $18 \mathrm{~mm}$. This brings the height of the specimen to $48 \mathrm{~mm}$. All bricks were conditioned by oven-drying them at $105^{\circ} \mathrm{C}$, and immersing them in water during 2 seconds just before mortar application to obtain good bonding. All specimens are tested at an age of 28 days. Curing was done in lab conditions $\left(20^{\circ} \mathrm{C}\right.$ and $60 \%$ relative humidity). In case of the hydraulic mortars, an initial wet curing of 7 days was respected. One set of the lime hydrate mortar specimens was subjected to high $\mathrm{CO}_{2}$ concentrations. After 28 days they were fully carbonated (observation after phenolphthalein spray test).

For each of the mortars, seven cylindrical specimens were tested. Four of them were pressed in an hydraulic press to estimate the compressive strength (outside the X-ray chamber); three were pressed inside the X-ray chamber and loaded up to fixed percentages of their estimated strength, at which point intermediate scans were performed. The applied X-ray source parameters were: $100 \mathrm{kV}$ and $0.35 \mathrm{~mA}$. The magnification was 3.8 and the pixel size 45.6 micron.

\subsection{Results}

Representative results for each brick-mortar combination are presented in fig. 3. Vertical as well as horizontal sections are presented, as obtained after the final loading step. Unfortunately, the resolution was not high enough to visualize the crack initiation, which is a micro-scale phenomenon. Only the larger meso and macro cracks were visible, which allowed to make a rough discrimination between different failure mechanisms. 


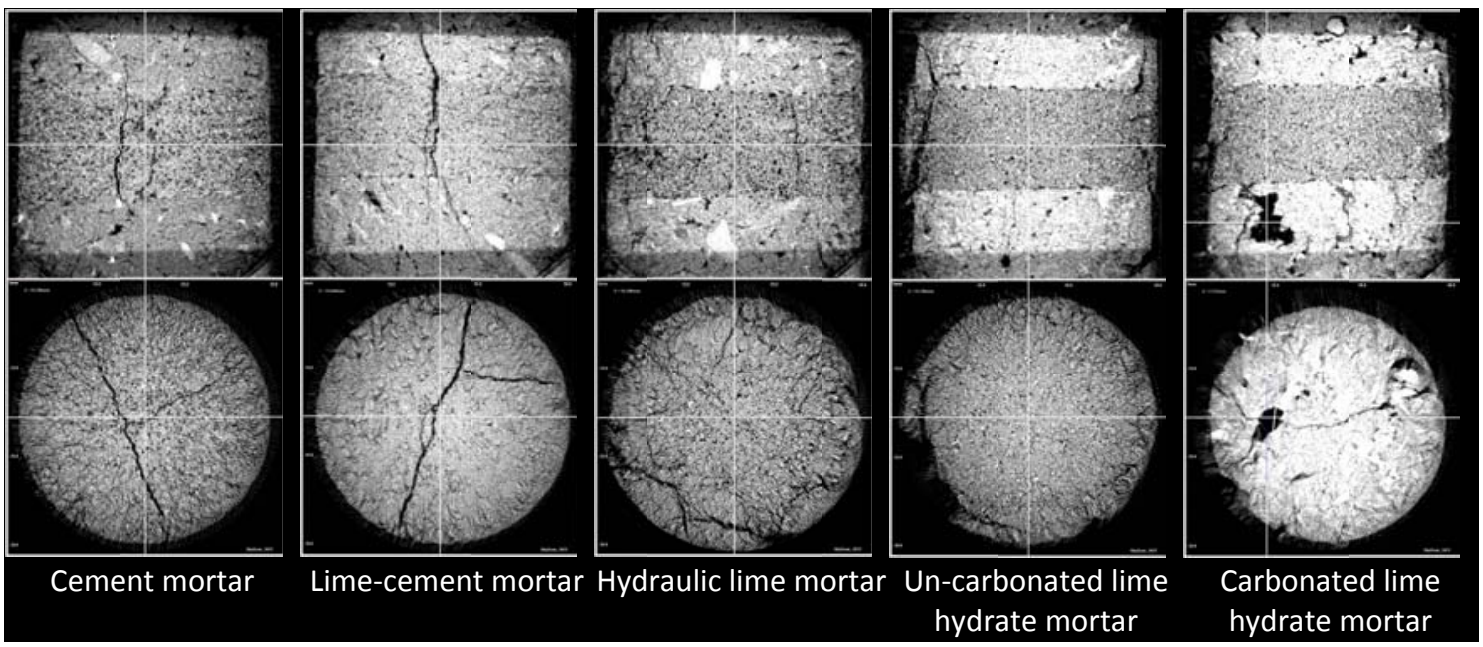

Figure 3: Vertical and horizontal section for crack visualisation after failure of the specimen [10]

For the cement mortar specimens, the cracking over the joint propagates into the brick at both sides. The vertical direction and the shape lead to the assumption that the crack is generated as a tensile crack due to the lateral expansion of the brick. On the other hand with the lime-cement mortar, the cracks are more inclined, which would be expected for sheartensile cracking. The different cracks are interconnected, but may have originated independently on different places. The crack pattern of the hydraulic lime mortar shows that the failure at the edges of the mortar joints leads eventually to continued cracking in the brick, still near the edges. No failure near the centre is observed, however the mortar appeared to be disintegrated after the test. The reason why there is no vertical tensile cracking in the brick, is that the bond may be defective: the shear stress developed in the interface is needed to generate the tensile stresses. The same is observed for the specimens with uncarbonated lime hydrate mortar, which has a similarly very low strength. An extra reason to doubt the bond quality with these two mortar types is the importance of the slow carbonation reaction for hardening, which has proceeded only over a limited depth at the age of 28 days. When the specimens are carbonated the picture is different: a crack is visible in the brick, and does not continue over the joint. In this case, bond can be expected to be developed more.

\section{THE INFLUENCE OF MOISTURE ON MICRO FRACTURE IN SANDSTONE}

\subsection{Problem statement}

Moisture is known to have a negative effect on the long-term behaviour of masonry and to decrease its mechanical characteristics. Among other techniques, microCT was applied to study the influence of moisture on the mechanical behaviour of ferruginous sandstone in order to understand and quantify this effect [14]. In this experimental program, the influence of moisture on the mechanical behaviour of ferruginous sandstone is investigated at different scales in order to obtain a more detailed picture of the acting processes: micro (sandstone inner structure), meso (sandstone blocks) and macro scale (masonry). In this paper, only results of the micro scale are discussed.

Final aim of the full test program is to assess the contribution of moisture ingress to the collapse of two historic structures which were constructed in Diestian ferruginous sandstone and to support the development of maintenance and restoration measures. 


\subsection{Test setup}

Three types of ferruginous sandstone are included in the study: low and high quality Diestian ferruginous sandstone and Brusselian ferruginous sandstone, with a compressive strength ranging from $1.5-15 \mathrm{MPa}$. The sandstone is composed of mainly quartz and limonite (acting as a ferruginous binder). The Diestian type also contains glauconite (around 20-30\%). A more detailed description of the composition and material characteristics can be found in [15].

In previous research, attempts were made to quantify the decrease in strength of ferruginous sandstone under saturated conditions, but no statistically significant result was obtained due to the large scatter on the strength values [16]. To overcome this problem and take into account the small amount of test material available (all test material comes from historic monuments), specimens with similar composition were applied for the current dry and wet compressive tests. For each test on a dry specimen, a related test on a saturated specimen which originated from the same drilled core was performed. This results in a 'paired' test, which still has restricted statistical significance but enables to observe the strength decrease in a more reliable manner. To estimate the strength and stiffness properties of the different types of sandstone, uniaxial 'paired' compressive tests were carried out on dry and saturated samples (diameter $50 \mathrm{~mm}$, height $60 \mathrm{~mm}$ ).

For microCT scanning, small cylindrical sandstone samples (diameter $\pm 10 \mathrm{~mm}$, height 14-15 mm) were scanned at different stages of a compression test. To enable stress application during scanning, a small, transparent compression cell was fabricated in polyetherimide (PEI). This compression cell allows to apply a constant compressive deformation while performing the scans, see fig. 4. The load is applied with a mechanical press outside the X-ray chamber, until a target stress level is reached. Then the cap of the compression cell is fixed. The moment at which the force is transferred from the mechanical press to the compression cell is marked by a small bud sudden force decrease on the digital output of the mechanical press. After fixation of the cap of the compression cell, the compressive strains within the sandstone specimen remain constant and a microCT scan is performed. This procedure is repeated until failure of the specimen. Since the strains are kept constant during scanning, this test is in fact a stepwise relaxation test. Aim is to perform 4 scans for each specimen (fig. 4): in the initial state, during elastic deformation, just before and just after reaching the maximum load level. Each scan has a duration of approximately 1.5 hour, resulting in a duration of at least 6 hours for each test. A total of 13 microCT tests were performed; at least two dry and two saturated samples for each type of ferruginous sandstone. A resolution of $7.8 \mu \mathrm{m}$ was achieved on a SkyScan 1172 system, with applied X-ray source parameters being $100 \mathrm{kV}$ and $0.1 \mathrm{~mA}$.

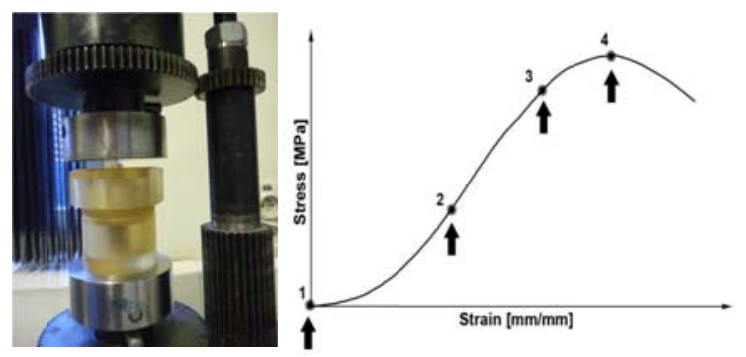

Figure 4: View of compression cell (left) and indication of targets for execution of the scans on a representative stress-strain curve [15]

The applied loading procedure introduces some error in the registration of the load levels and the indicated stresses can thus not be seen as accurate quantitative values. In addition, the small size of the specimens and roughness of the surface at the loaded ends also introduce inaccuracies in the estimated average compressive stress. Therefore, a precise quantification of the acting stresses was not aimed for.

Taking into account the experience from the tests on the masonry couplets (discussed in Section 2), the specimen size was chosen as small as possible to ensure a sufficiently high scan resolution, but could not be reduced any 
further as the volume would no longer be representative for low quality Diestian ferruginous sandstone. This sandstone type contains grains and coagulated fragments having a size up to $1 \mathrm{~mm}$, only 10 times smaller than the chosen specimen diameter.

\subsection{Results}

As a result of the microCT tests, horizontal slices were obtained which show the inner structure of the ferruginous sandstone samples during the stepwise compression tests. Representative microCT results of a dry, Brusselian sandstone and saturated, low quality Diestian sandstone sample are presented in fig. 5. An indicative porosity value, as calculated form the scan images, is indicated below each image. Also the related stress-axial strain curves with an indication of the scan moments are presented. In these graphs, the small stress increase during fixation of the cap of the load cell and stress losses due to relaxation during scanning are not shown, since they could not be recorded with the applied setup [15].

The 'paired' compressive tests indicated a decrease of $40-60 \%$ in compressive strength for the saturated samples, with a larger decrease for the lower quality test specimens. Comparing the results of the stress-strain curves and from the microCT images, it is observed that the saturated samples show a less brittle behaviour with a more progressive crack growth smeared out over a longer time period, compared to the dry test specimens. On the scans of the saturated samples, the crack initiation and growth was observed in an early stage during the compression test. The effect of saturation was thus quantified by comparing results for dry and saturated samples of the same sandstone quality. In addition, the influence of cementation degree, grain size distribution and clay content was observed when comparing results from different sandstone qualities.

In general, the scan resolution was not sufficient to observe the very initiation of micro cracks and the behaviour of the clay minerals. However, crack propagation, quartz grains $(0.1-1 \mathrm{~mm})$, coagulated clay fragments and relatively large pores could be distinguished on the microCT results.

\section{THE INFLUENCE OF CONCRETE FLOW ON SPATIAL DISTRIBUTION AND ORIENTATION OF FIBRES IN STEEL FIBRE REINFORCED SELF- COMPACTING CONCRETE}

\subsection{Problem statement}

Steel fibre reinforced self-compacting concrete (SFRSCC) combines the benefits of self-compacting concrete (SCC) in the fresh state with the enhanced performance of fibre reinforced concrete (FRC) in the hardened state. For the design of structural elements, fibres are often assumed to have a homogeneous and isotropic reinforcement contribution [17]. By better understanding the mechanisms that influence the spatial distribution and orientation of the fibres, it is possible to increase the number of applications where SFRSCC is an economically competitive solution.

The distribution and orientation of the fibres is of great interest since the residual tensile strength and the toughness of the composite material is proportional to the number and the orientation of effective fibres bridging a crack. Therefore, the influence of the flow distance on fibre distribution and orientation is investigated in SFRSCC by means of X-ray computed tomography [18].

\subsection{Test setup}

Two steel fibre reinforced self-compacting concrete mixtures are investigated in this study. Both self-compacting concrete compositions are designed so as to obtain SCC mixtures with a similar flowability but a different viscosity (and compressive strength) in order to examine the impact of this viscosity on the flow-induced fibre orientation and the spatial distribution of the fibres. The mixture proportions can be found in [18]. The fibre content is kept constant at $30 \mathrm{~kg} / \mathrm{m}^{3}(\approx 0.38$ vol\%) of hooked-end steel fibres. 


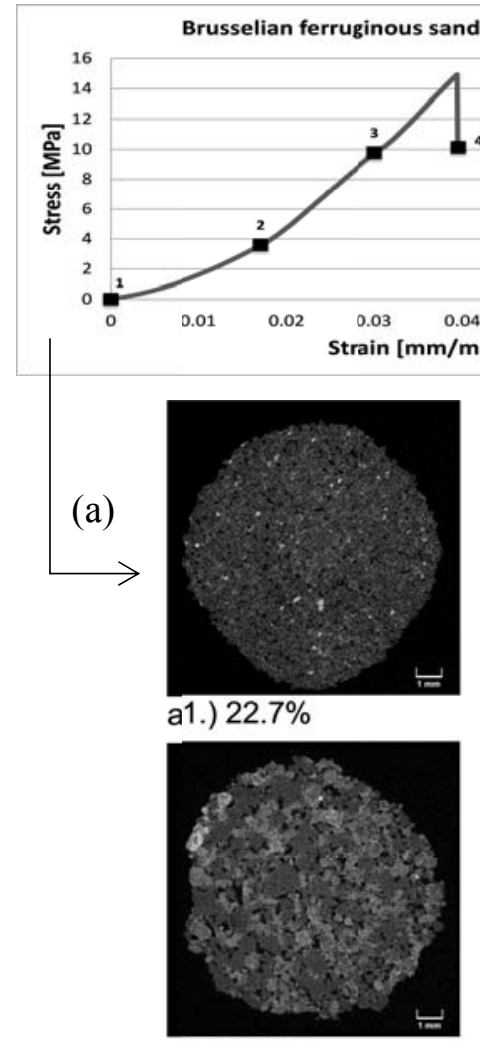

b1.) $23.5 \%$

Figure 5: Results of microCT on stepwise loaded ferruginous sandstone: stress-strain graph of dry, Brusselian (a) and saturated, low-quality Diestian (b) sample. Horizontal slices with indication of 2D porosity [15].

The constituent materials are first mixed in a counter-current batch mixer with only $80 \%$ of polycarboxylate ether (PCE) superplasticiser. Collated hooked-end steel fibres are then gradually added to avoid fibre balling and finally the remaining $20 \%$ of superplasticiser is added.

The filling ability of the concrete has to be sufficient to fill a formwork of 2 metre length solely under the influence of its own weight. As it is also intended to obtain a self-levelling concrete, the slump flow value (SF) is kept constant between 750 and $800 \mathrm{~mm}$. For every fibre type, three batches of concrete are produced. The concrete properties are presented in [18] as the average value of three measurements. For each batch of concrete the compressive strength is determined on six $150 \mathrm{~mm}$ cubes according to EN 12390-3, with

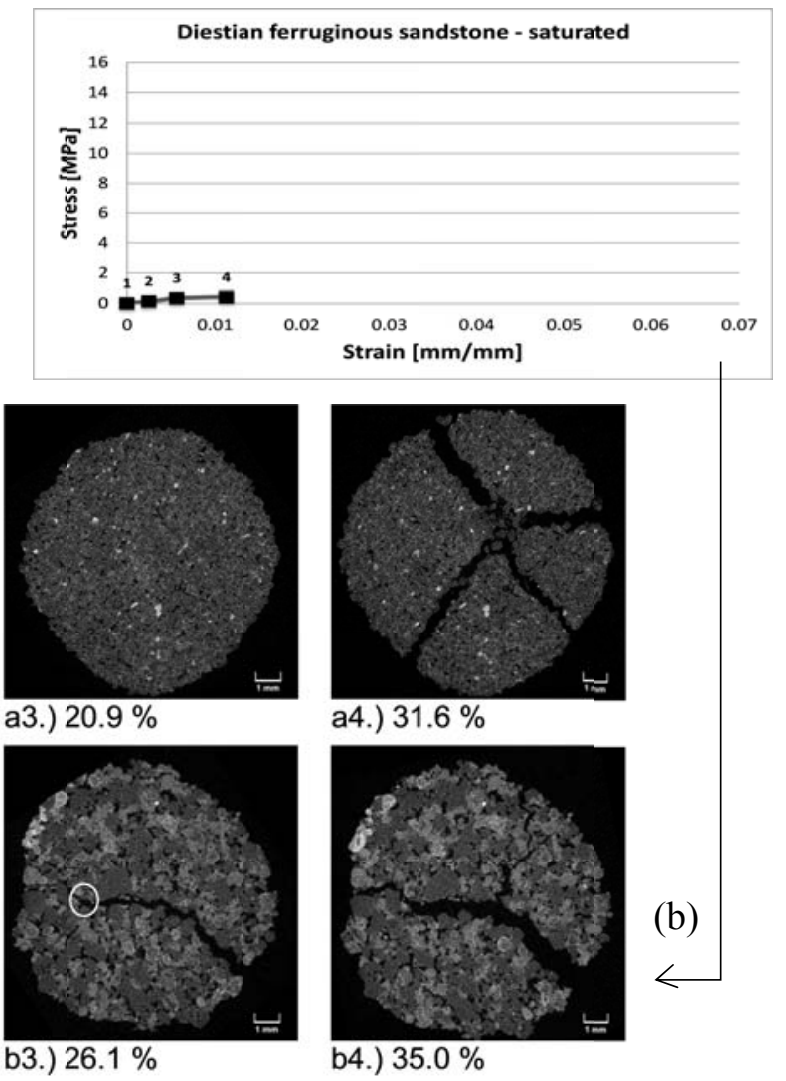

mean cube compressive strength ranging between 52 and $75 \mathrm{MPa}$.

For each fibre type, six beams with a length of $2.05 \mathrm{~m}$ and a cross-section of $150 \mathrm{~mm}$ by $150 \mathrm{~mm}$ are cast from one side of a long, narrow formwork using a chute. After curing and demoulding, these beams are cut in three different prisms $\left(150 \times 150 \times 600 \mathrm{~mm}^{3}\right)$.

These prisms are tested under three-point bending load, according to EN 14651, to determine the post-cracking behaviour in function of the flow length. The test is performed under crack mouth opening displacement (CMOD) control.

For half of the SFRSCC beams (3 out of 6 beams for each fibre type), the number of fibres in every cracking plane after a threepoint bending test is manually counted. In order to get information on how the fibres are distributed over the cross-section, each cross- 
section is divided into 36 equal parts of about $25 \mathrm{~mm}$ by $25 \mathrm{~mm}$. In addition, a photograph of every sawn section of these beams is made on which the number of fibres is automatically counted using image analysis. The same template as for the manual counting is used.

In order to measure the fibre dosage, spatial distribution and the fibre orientation in three dimensions, X-ray computed tomography is used on core samples with a diameter of $100 \mathrm{~mm}$. The longitudinal axis of the core corresponds to the longitudinal axis of the beams and hence with the flow direction of the concrete. For each drilled core, more than 3000 X-ray photographs are taken (one projection every 2 milli radians). A resolution of $81 \mu \mathrm{m}$ was achieved on Nikon Metrology XT H450 system, with applied X-ray source parameters being $360 \mathrm{kV}$ and $0.205 \mathrm{~mA}$.

Subsequently, a three dimensional reconstruction is made with all these projections. Thanks to the difference in density between steel and the concrete matrix, the exact position of the fibres can be deduced from this volume data. The outer surface of the fibres (in three dimensions), is stored as an STL file which is used to calculate the volume percentage of fibres in the sample and their orientation coefficient.

\subsection{Results}

From the results of the three-point bending test, the post-cracking behaviour is determined. For the majority of the beams, the central prisms show the best post-cracking behaviour. Fibres align with the longitudinal axis of the beam while the concrete fills the formwork. The reason why the post-cracking strength of the last prism decreases again is because at the end of the beam, streamlines are affected by the fact that the concrete approaches the end of the beam. The difference is, however, found to be small.

From the manual counting, steel fibres are found to be evenly distributed over the crosssection and the wall-effect as a result of the boundary conditions (formwork) is not very clear [19]. In the top $25 \mathrm{~mm}$ of the cross- section, the number of fibres is the smallest $(13.5 \%)$ which may indicate very limited static segregation. It is noteworthy that the number of fibres in the upper third of the beam is mostly smaller in a cross-section near the casting point. This is the case for all types of fibres used in this study, but is more pronounced for the fibres with a length of 60 $\mathrm{mm}$ than for the shorter fibres.

The results are compared to a 3D representation obtained from microCT. 2D representations show that the steel fibres have a pronounced preferential orientation in the direction of the longitudinal axis of the beam. Independent from the viscosity of the mixture, preferential fibre orientation is induced by shear flow of the concrete. Fig. 6 shows the fibre orientation in a concrete beam reinforced with fibres with length $60 \mathrm{~mm}$ and a diameter of $0.71 \mathrm{~mm}$. Although $30 \mathrm{~kg}$ of steel fibres per $\mathrm{m}^{3}$ of concrete was carefully weighed for each mixture and every batch was thoroughly mixed, the volume percentage of fibres can show local variations. On average, the percentage by volume is $0.38 \%$. The orientation coefficients at each cracking-plane and sawn surface in the beam are corrected with the experimentally measured volume percentage of fibres. By doing so, the orientation coefficients determined with different measurement methods are in good agreement with each other (fig 7).

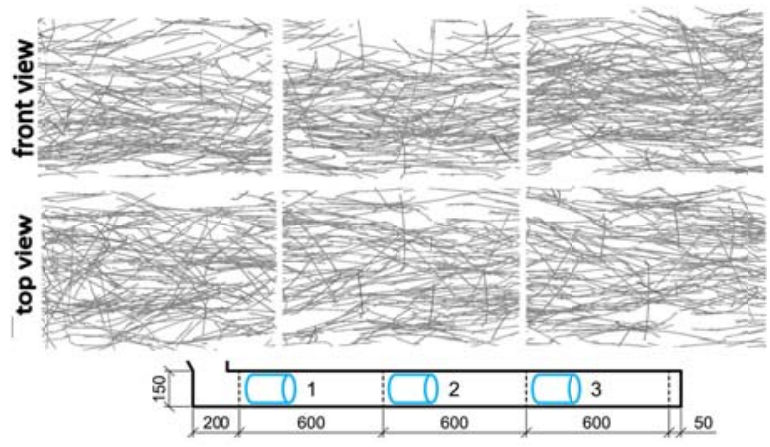

Figure 6: Front view and top view of three core samples [18]

A possible explanation for the smaller volume percentage of fibres near the casting point is that the gate of the chute is only opened after the chute is filled with concrete. 
During the filling process, limited static segregation in the chute may occur. Concrete that is originally located at the top of the chute is, after pouring the beam, part of the first specimen and may therefore have a smaller fibre amount. The corrected values for the orientation coefficient show that fibres already have a preferential orientation near the casting point as a result of flow-induced orientation in the chute, which then increases only a little more in the beam itself.

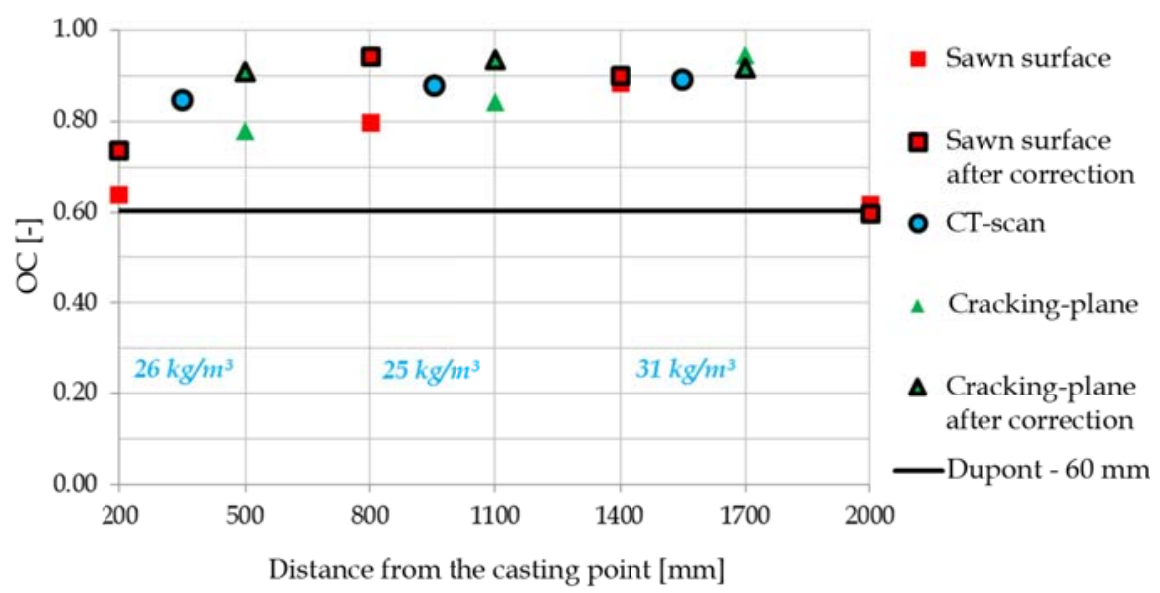

Figure 7: Orientation coefficient after correction as a function of the distance from the casting point

\section{DISCUSSION AND FURTHER RESEARCH}

In all test programs, microCT was applied and related to other measurements in order to visualize the results and to investigate the effectiveness of the visualization technique. Most test results supported the theoretical framework relevant to the effects of varying conditions (relative stiffness, pore saturation, viscosity) on the observed failure modes or fibre alignment.

However, balance between sample size and image resolution remains an important focus point. In the first test program [10] the analysis was complicated by two phenomena. Firstly, the resolution was too low to differentiate between related mortar types, such as carbonated and un-carbonated lime mortars and to observe the initiation of the cracks or a pore collapse mechanism. Secondly, the limited size of the samples increases the effect of boundary conditions, which can interfere with the failure mechanisms. Also in the second test program [15] the specimen size was chosen as small as possible to ensure a sufficiently high scan resolution, but could not be reduced any further as the volume would no longer be representative for the tested sandstone. Due to the spatial resolution and required duration for the intermediate scanning steps, micro crack initiation could not be observed.

Based on the experience gained during the discussed test programs, following research programs are currently being developed:

Firstly, microCT will be used to investigate the bond behaviour at the interface between reinforcement and concrete. The third test program discussed in this paper was a first step to obtain a global image of the inner structure of a concrete sample for defining the orientation of fibres in SFRSCC. In this view, a first topic will focus on bond behaviour in the interface between concrete and steel fibres in FRC subjected to fatigue loading. A second topic will combine the acoustic emission (AE) technique and microCT to better understand the mechanical effects of corrosion induced damage at the reinforcement-concrete interface. The resulting $\mathrm{AE}$ parameters and waveforms will be correlated to the damage observed by microCT in subsequent stages of the corrosion process. 
Secondly, results obtained by microCT will be applied to evaluate numerical models, such as discrete element models which are currently under development. For this purpose, the results of the microCT tests on ferruginous sandstone (second test program) can be applied. The setup of the X-ray scanning on masonry couplets will be further optimized and scans will be repeated with higher resolution in the framework of an ongoing project which focusses on the influence of different brick-mortar compositions on the failure modes of masonry under compression. The models under development are required input in further research in advanced numerical modelling to couple the mechanical behaviour at the material level with the structural performance at the component level.

\section{CONCLUSIONS}

Microfocus X-ray computed tomography offers interesting possibilities to visualize the inner structure of materials and to observe failure mechanisms. In this paper, three studies of the Building Materials and Building Technology research group of the KU Leuven were presented. For each test program, setup optimization and resulting failure modes were discussed. Sample size, image resolution, combination with acoustic emission data and strain mapping as obtained from microCT and from numerical modelling are the most important focus points in the development of future research programs.

\section{REFERENCES}

[1] Wevers M. X-ray Computed Tomography for Non-Destructive Testing, in Conference on Industrial Computed Tomography (ICT). Shaker Verlag, NDT.net: Wels, Austria. 2012.

[2] Wevers M., de Meester P., Swennen R. Microfocus X-ray computer tomography in materials research. Insight 2001; 43(10):658-663.
[3] Vervoort A., Wevers M., Swennen R., Roels S., Van Geet M., Sellers E. Recent advances of X-ray $\mathrm{CT}$ and its applications for rock material. X-Ray $\mathrm{Ct}$ for Geomaterials Soils, Concrete, Rocks 2004:79-91.

[4] Cnudde V., Dewanckele J., Boone M., de Kock T., Boone M., Brabant L., et al. High-Resolution X-Ray CT for 3D Petrography of Ferruginous Sandstone for an Investigation of Building Stone Decay. Microscopy Research and Technique 2011; 74(11):1006-1017.

[5] Landis E.N., Nagy E.N. Threedimensional work of fracture for mortar in compression. Engineering Fracture Mechanics 2000; 65(2-3):223-234.

[6] Michel A., Pease B.J., Geiker M.R., Stang H., Olesen J.F. Monitoring reinforcement corrosion and corrosion-induced cracking using non-destructive $\mathrm{x}$-ray attenuation measurements. Cement and Concrete Research 2011; 41(11):1085-1094.

[7] (ACI) A.C.I. Report on nondestructive test methods for evaluation of concrete in structures. USA. 2013.

[8] Roels S., Carmeliet J. Analysis of moisture flow in poreus materials using microfocus X-ray radiography. International Journal of Heat and Mass Transfer 2006; 49:4762-4772.

[9] Brooks R.A., Chiro G.D. Beam hardening in $\mathrm{X}$-ray reconstructive tomography. Physics in Medicine and Biology 1976; 21(3):390-398.

[10]Hendrickx R., Buyninckx K., Schueremans L., Kerckhofs G., Verstrynge E., Wevers M., et al. Observation of the failure mechanism of brick masonry doublets with cement and lime mortars by microfocus X-ray computed tomography, in 8th International Masonry Conference: Dresden, The Netherlands. 2010.

[11]Hayen R., Van Balen K., Van Gemert D. The mechanical behaviour of mortars in triaxial compression, in 4th International Seminar on Structural Analysis of Historical Constructions, Modena C., Lourenco P.B., Roca P., Editors. 
Balkema: Padova. 2004. p. 611-618.

[12] Hilsdorf H.K. Investigation into the failure mechanism of brick masonry loaded in axial compression, in Designing, engineering and construction with masonry products, Johnson F.H., Editor. Gulf Publishing: Houston (Texas). 1969. p. 34-41.

[13] Verstrynge E., Schueremans L., Van Gemert D. Time-dependent mechanical behavior of lime-mortar masonry. Materials and Structures 2010; 44(1):2942.

[14] Verstrynge E., Adriaens R., Elsen J., Van Balen K. Multi-scale analysis on the influence of moisture on the mechanical behavior of ferruginous sandstone. Construction and Building Materials 2014; 54:78-90.

[15] Verstrynge E., Pyka G., Van Balen K. The influence of moisture on the mechanical behaviour of sandstone assessed by means of micro-computed tomography, in 9th International Masonry Conference: Guimaraes, Portugal. 2014.

[16] Verstrynge E. Long-term behaviour of monumental masonry constructions: modelling and probabilistic evaluation. $\mathrm{PhD}$ Thesis. Civil Engineering Department, KU Leuven: Leuven. 2010.

[17] Di Prisco M., Plizzari G., Vandewalle L. Fibre reinforced concrete: new design perspectives. Materials and Structures 2009; 42(1261-1281).

[18] Andries J., Van Itterbeeck P., Vandewalle L., Van Geysel A. Influence of concrete flow on spatial distribution and orientation of fibres in steel fibre reinforced selfcompacting concrete, in fib Symposium: Copenhagen, Denmark. 2015.

[19] Dupont D., Vandewalle L. Distribution of steel fibres in rectangular sections. Cement \& Concrete Composites 2005; 27(3):391-398. 